\title{
A GENEALOGIA DO AMOR EM HILDA HILST
}

Enivalda Nunes Freitas e SOUZA (UFU)

RESUMO: Em Cantares, Hilda Hilst dedica-se à construção da imagem do amor: amante e amado raramente se encontram e sempre se desencontram reencenando os ritos amorosos que os homens sonharam e que os mitos e os poemas perpetuaram. Para o desenvolvimento desse tema, este artigo ancora-se nos mitos platônicos, Eros e sua genealogia complexa e os andróginos desafortunados, reveladores da contingência amorosa que se desdobra e metamorfoseia progressivamente no testemunho da busca infindável de um gozo jamais fruído.

PALAVRAS-CHAVE: Poesia brasileira contemporânea; Hilda Hilst; Imaginário; Mitos platônicos; Amor; Cantares.

ABSTRACT: In Cantares, Hilda Hilst is dedicated to building the image of love: lover and beloved rarely meet each other and always get lost of each other, rearranging the romantic rituals that men dreamed and that the miths and poems have perpetuated. In order to develop this theme, this article is anchored in the Platonic miths, Eros and his complex genealogy and the androgynous unfortunated, revealers of the contingency of love that unfolds itself and metamorphoses gradually in the testimony of an endless pursuit of a never enjoyed pleasure.

KEYWORDS: Brazilian contemporary poetry; Hilda Hilst; Imaginary; Platonic myths; Love; Cantares.

Já uma escritora pronta, Hilda Hilst publica em 1983 Cantares de perda e predileção, obra com setenta poemas, e Cantares do sem nome e de partidas, com dez, em 1995. Esses dois livros estão reunidos em obra única sob o título de Cantares, em 2002, pelo professor Alcir Pécora. Nestas duas obras, a poeta dedica-se à construção da imagem do amor: amante e amado raramente se encontram e sempre se desencontram reencenando os ritos amorosos que os homens sonharam e que os mitos e os poemas perpetuaram. Assim, Eros e sua genealogia complexa, os andróginos desafortunados, Narciso e seu reino de sombra, além da profusão das imagens cósmicas, vão revelando a contingência amorosa que se desdobra e metamorfoseia progressivamente no testemunho da busca infindável de um gozo jamais fruído. 
Os livros de Cantares são subsequentes ao Da morte. Odes mínimas, obra de 1980, em que a poeta promove uma interlocução amistosa e domesticadora com a morte, trazendo-a para a intimidade quotidiana. Desta forma, dos cinquenta aos sessenta e cinco anos de idade, Hilst enlaça e perscruta os dois grandes princípios, oponentes e complementares, da experiência humana, o amor e a morte, temas clássicos da arte. Como se perceberá mais adiante, um abre-se ao outro, considerando que, freudianamente, os Cantares bíblicos já afirmavam: "O amor é forte como a morte" (“Cântico" 8: 6).

\section{A totalidade perdida}

No mito do andrógino relatado por Platão em $O$ banquete, o filósofo assinala que havia três gêneros - o masculino, o feminino e o andrógino -, os quais participavam dos dois sexos. Os homens, antes duplos e completos, foram separados por Zeus com a intenção de fragilizá-los, pois a força dos homens - eles contavam com quatro braços, quatro pernas e andavam muito rapidamente em movimentos circulares - os tinha transformado em seres arrogantes e orgulhosos, tanto que tentaram "fazer uma escalada ao céu, para investir contra os deuses" (PLATÃO, 1979, p. 23). Mediante tamanha insolência, vem a punição: para não aniquilar totalmente a espécie (quem renderia, afinal, homenagem aos deuses?), Zeus decide dividi-los ao meio. A narrativa prossegue:

Por conseguinte, desde que a nossa natureza se mutilou em duas, ansiava cada um por sua própria metade e a ela se unia, e envolvendo-se com as mãos e enlaçando-se um ao outro, no ardor de se confundirem, morriam de fome e de inércia em geral, por nada quererem fazer longe um do outro. [...] É então de há tanto tempo que o amor de um pelo outro está implantado nos homens, restaurador da nossa antiga natureza, em sua tentativa de fazer um só de dois e de curar a natureza humana. (PLATÃO, 1979, p. 23 24).

Assim, o amor nasce dessa privação. A falta que se conhece em nós nada mais é que o desejo de preencher o espaço vazio que essa separação original imprimiu. De espécie incompleta, cada qual procura sua metade perdida. O homem, que era parte de outro, dedica sua procura e seu amor aos de sua espécie; de igual forma, a mulher que era o complemento de outra mulher não se interessa por outros que não sejam de sua espécie. Por outro lado, o homem que fazia parte da espécie andrógina, procura pelo oposto de seu sexo, a mulher, que era seu complemento, e, assim, vice-versa. Esse 
trecho encerra com o registro de que o amor é a cura da natureza humana, no que se refere a esta nostalgia de um tempo em que se era perfeitamente completo.

Mais adiante, o narrador diz que, quando cada um encontra e permanece junto da sua metade, se Hefesto lhes aparecesse com suas ferramentas de forja propondo-lhes fundir em um só, como elucida o fragmento logo a seguir, ninguém seria capaz de dizer não, pois este é o maior desejo do homem, viver em amor, pois encontrar o amor é recuperar a totalidade perdida. Nessa medida, a fusão no outro, metade anelada para a inteireza do si, nesse amor total que reintegraria a fragmentação, ocorre de maneira que

[...] nem de noite nem de dia vos separeis um do outro [...] de modo que de dois vos torneis um só e, enquanto viverdes, como uma só pessoa, possais viver ambos em comum, e depois que morrerdes, lá no Hades, em vez de dois ser um só, mortos os dois numa morte comum. (PLATÃO, 1979, p. 25).

No entanto, à luz do mito de Narciso e seus estudiosos, o amor sobrevive mesmo é da falta; o que lhe alimenta, como dirá Freud, é o impulso de morte.

Em Cantares do sem nome e de partidas perpetuam-se as eternas contradições do amor que causam tormentos na alma e no corpo. Mas, diferentemente de Cantares de perda e predileção, quando o sujeito amante entrega-se desesperadamente ao amado, procura-o e confunde-se com ele, numa batalha sem fim, parece que a exaustão chega aos últimos cânticos, pois agora o amor é "de partida" e seu nome é "Nunca Mais", ainda que haja "ilusões e assomos" e "repentes de perpetuar a Duração".

O primeiro poema não nega a fadiga instaurada pela carência de algo que jamais se atinge, mas que é a própria razão de sua existência mitigada, longe, ao final dos versos, de levar à transcendência que se espera do amor, pois a amante, diminuída cada vez mais, em vez de elevar-se, desce ao mundo ctônico, volve às profundezas, remexe o "fulgor das trevas", até fazer-se "aranhas e formigas". Assim começa o primeiro poema: 
Que este amor não me cegue nem me siga.

E de mim mesma nunca se aperceba.

Que me exclua do estar sendo perseguida

E do tormento

De só por ele me saber estar sendo.

(p.17). [1]

A quase paronomásia de "cegue" e "siga" já antecipa o tormento que é viver em amor. Aliás, como afirmam gregos, psicanalistas e cristãos, o amor é o princípio de tudo, amar é viver, daí que amar é morrer, sobretudo quando se ama a si mesmo como deveria amar o outro, como o fez Narciso. Nestes versos, o amor que deveria ser fonte de luz é fonte de trevas. Contudo, intermediário entre os homens e os deuses, o amor é mesmo a perfeita beleza, aquela do mundo elevado, onde habitam as almas puras, incorruptíveis e, nesse caso, o amor é a morada de Deus:

Que o olhar não se perca nas tulipas

Pois formas tão perfeitas de beleza Vêm do fulgor das trevas.

E o meu Senhor habita o rutilante escuro

De um suposto de heras em alto muro.

(p.17).

Na sua aparência, o amor é delicado e atraente, tangível e envolvente, cuja imagem, não passando de uma armadilha, pode levar à perdição, pois suas profundezas são insondáveis, desarrazoáveis. "Trevas", "muro", "escuro" compõem o jardim do amor, visto numa das mais belas e enigmáticas flores, a tulipa. Desta forma, tal qual no mito da tulipamania que invadiu a Holanda do século XVII, encantada com a flor persa, quando uma tulipa valia mais que um porco ou uma tonelada de trigo, o que causou um grande estrago na economia pelo seu falso valor[2], o amor leva da euforia ao desapontamento, brota do calor das entranhas e fenece ao mais leve toque.

Ainda sobre a tulipa, considerada a flor dos apaixonados, há uma lenda persa sobre a origem da tulipa negra, flor rara e preciosa, nascida das lágrimas de um amor rejeitado. Diz a lenda: "uma moça chamada Ferhad apaixonou-se por um rapaz 
chamado Shirin. Vendo seu amor rejeitado, Ferhad fugiu para o deserto. Ao chorar de saudades e tristeza, cada uma de suas lágrimas, ao tocar a areia, transformou-se em uma linda tulipa"[3]. Como se sabe, a tulipa não é a primeira flor que brota de uma frustração amorosa, antes dela houve narciso. Que amor é esse que deixa a amante "farta de fadigas. E de fragilidades tantas" (17)? É longa a tradição do amor-martírio, como no verso de Camões, "Ó tirânico Amor, ó caso vário", lembrado por Hilst na epígrafe desses Cantares do sem nome e de partidas.

Os poemas seguintes cumprem a promessa do - Cantares do sem nome e de partidas -ao tempo em que evocam os espaços vazios, de solidão, de luto e de partidas como a morada do amor. O desejo da amante é ser encontrada "no não merecimento das conquistas", sempre partindo, com valises e sobretudo, "nas plataformas, nas escadas". Esse amor andarilho, carente, mendigo, "desabitado de carícias", é o filho de Penia, jamais satisfeito, pela própria natureza. Mendigar é o seu suplício.

No segundo poema, a imagem de partida se completa com o navio. O navio que parte assemelha-se ao dorso: a viajante desgostosa oculta, pelos seus costados, gozo e fulgor, lágrimas incendidas de uma profundeza condenada a ser desconhecida pelo outro, mas, de algum modo, marcada pelo desejo, fruído ou não realizado:

Dorsos de luz de águas mais profundas. Peixes.

Mas sobre mim, intensas, ilhargas juvenis

Machucadas de gozo.

E que jamais perceba o rocio da chama: Este molhado fulgor sobre o meu rosto.

(p.18).

O conjunto imagético composto por luz, águas, peixes e ilhargas forma uma representação erótica pulsante e superior à latência da própria negação. A amante está cercada, por todos os lados, das águas primaveris fecundantes e fálicas, mas o amor é feito de um jogo insano, pela tensão paradoxal que lhe é inerente. Como explica Freud, em Além do princípio de prazer, a realização amorosa é a dissolvência, é a volta ao 
estado inorgânico e primitivo, é o repouso que se assemelha à morte. Então, o gozo do amor nada mais é que o exercício da pulsão de morte, levando a amante, sedenta de amor e de vida, à sua fuga constante, "Como se só na morte abraçasses a vida." (p.20). Mas, como pode? Como nomear sentimento tão cambiante? Neste tentame, segue a amante sua busca especulativa:

Isso de mim que anseia despedida (Para perpetuar o que está sendo) Não tem nome de amor.

A origem do amor não provém do céu ou da terra - "Nem é celeste ou terreno" (p.19) - e não pode ser explicada pelas esferas espirituais ou humanas, nem se pode dizer que seja sagrada ou profana. Lançado para o corpo, o amor se torna mais premente, anseia pelo impossível que julga existir, como se existisse o avesso do tigre, sua parte mansa e suave. Tenta-se explicar o amor pelo sensitivo, pelas complexas emanações sensórias, como em "marulhoso", "tenro", "dançarino", sonoridades que reverberam movimentos que se deslocam continuamente. O amor é delicado e aprazível ao toque, porém não pode ostentar o nome de amor, porque é mais que isso preferindo “ausência e desconforto/ Para guardar no eterno o coração do outro.” (p.19).

Em poemas seguintes, a poeta vai dizer que esse sentimento "só se ajusta ao Nunca. Ao Nunca Mais." (p.20), alertando, logo em seguida, que "Nem é corvo ou poema o Nunca Mais.” (p.21). Vale lembrar o caráter enigmático do nevermore grasnado pelo corvo de Poe que serve como resposta para todas as perguntas do moço desesperado: as alegrias, os amigos e Lenora, o amor virgem para sempre perdido. Desta forma, o desencanto assinalado pelo "Nunca Mais" refere-se ainda àquela falta original, à ilusão simultânea de estar sendo, ter sido, uma vez que ultrapassa a referencialidade do célebre poema evocado, resguardando dele sua essência simbólica alusiva ao vazio da condição humana. 


\section{Poros e Penia, pais de Amor}

O mito do andrógino em Platão explica o amor como via para recuperar a totalidade perdida, mas não ilustra a origem do amor, isto é, quem o gerou ou de onde ele vem. Ainda em $O$ banquete, Platão narra o mito do nascimento do amor que, longe de ser aquela promessa de felicidade eterna e completa, verificável no mito do andrógino, chama para si uma penúria lastimável, pela sua dupla origem, como escreve o pensador:

Quando nasceu Afrodite, banqueteavam-se os deuses, e entre os demais se encontrava também o filho de Prudência, Recurso. Depois que acabaram de jantar, veio para esmolar do festim a Pobreza, e ficou pela porta. Ora, Recurso, embriagado com o néctar - pois vinho ainda não havia - penetrou o jardim de Zeus e, pesado, adormeceu. Pobreza então, tramando em sua falta de recurso engendrar um filho de Recurso, deitase ao seu lado e pronto concebe o Amor. (PLATÃO, 1979, p. 35).

Essa passagem impele a uma correção do pensamento corrente: Eros não é filho de Afrodite, mas a ela está muito ligado, nasce sob sua égide. De certo modo, a origem de Eros é mais embaraçosa: seus pais formam um casal dissonante em que o equilíbrio nada mais é do que a junção de opostos irreconciliáveis. Recurso vem do grego Poro que significa "o Imaginoso", personificado, também, como "recurso", "passagem", "via". Por sua vez, Pobreza é Penia, a carência e a indigência. Recurso é imortal, Pobreza é mortal, daí o amor como se conhece, ou seja, jamais satisfeito pela insuperável carência. O amor humilha-se, mendiga, implora, vive de lar em lar, mas sempre encontra recursos para sua realização, pois é altivo e ardiloso, apreciador da beleza e desejoso do belo e do bom:

E por ser filho o Amor de Recurso e de Pobreza foi esta a condição em que ele ficou. Primeiramente ele é sempre pobre, e longe está de ser delicado e belo, como a maioria imagina, mas é duro, seco, descalço e sem lar, sempre por terra e sem forro, deitando-se ao desabrigo, às portas e nos caminhos, porque tem a natureza da mãe, sempre convivendo com a precisão. Segundo o pai, porém, ele é insidioso com o que é belo e bom, e corajoso, decidido e enérgico, caçador terrível, sempre a tecer maquinações, ávido de sabedoria e cheio de recursos (PLATÃO, 1979, p. 35). 
Estas características situam o amor como um intermediário entre mundos e situações opostas: divino e terreno, mortal e imortal, ideal e real. Por sua natureza ambígua, Hilst vai dizer do amor "doloso e penitente", o que é mesmo a síntese do seu dinamismo, da sua transitividade natural. Nos versos seguintes, a fusão das características sagrado e profano, virilidade e docilidade, benignidade e belicosidade, altivez e submissão, humildade e penúria, são evocadas pelo mito como se observa nos versos:

Tem muito de sedução, armadilhas, minúcias

Isso sem nome fere e faz feridas.

Penitente e algoz

Com ares de santidade

Odores de cortesã, pode ser carmelita

Ou Catarina, ser menina ou malsã.

(p.20).

Como o amor é dinâmico, poria, seu caráter é instável, para lhe assegurar as constantes carência e providência, como sugerem os versos: "É de perpetuidade no que pensas efêmero / E breve e pequenino / No que sentes eterno." (p.21); "tem fome. / De formosura, desgosto, ri / E chora. Um tigre passeia o Nunca Mais.” (p.22). A imagem do tigre é reiterativa no cancioneiro amoroso de Hilda Hilst. Segundo a psicologia das profundezas, esse animal está associado à cólera e à crueldade, por estar vinculado a Dionísio (CIRLOT, 1984, p. 571). Mas, em Hilst, esta fera selvagem converte-se em seu duplo, a fera domada, erótica, de cujos pelos brilhantes e sedosos se advinha a maciez da pele, o convite ao aconchego amoroso. Diz a poeta: "Um tigre te persegue. / E perseguido és novo, devastado e outro" (p.22). São as porias vivificantes do amor, que não conhece o nojo depois de fartado, pois o tigre-amor está atado à nossa "própria envoltura" e é "manchado de quimeras". Paralelamente ao "tigre", "quimera" pode bem evocar, além da fantasia imorredoura, companheira do amor, a Quimera mítica, o ser de estrutura complexa e promíscua, símbolo da perversão. E, assim, vai-se perpetuando o amor com sua eterna fome, mesmo em face de cada desengano. É neste momento que a poesia entra como sacrário e arauto desse amor que jamais se rende às suas misérias: "Canta o começo e o fim. Como se fosse verdade / A esperança". (p.25). 
Como se fosse verdade encantações, poemas

Como se Aquele ouvisse arrebatado

Teus cantares de louca, as cantigas da pena.

Como se a cada noite de ti se despedisse

Com colibris na boca.

E candeias e frutos, como se fosses amante

E estivesses de luto, e Ele, o Pai

Te fizesse porisso adormecer...

(Como se se apiedasse porque humana

És apenas poeira,

E Ele o grande Tecelão da tua morte: a teia).

Como se fosse vão te amar e por isso perfeito.

Amar o perecível, o nada, o pó, é sempre despedir-se.

E não é Ele, o Fazedor, o Artífice, o Cego

O Seguidor disso sem nome? ISSO...

O amor e sua fome.

(p.26).

Este último poema de Cantares do sem nome e de partidas é introduzido por uma "comparação hipotética ou subjetiva", "como se", cujo elemento comparativo vem dos poemas anteriores e é a síntese desse livro: "o amor e sua fome", o viver o amor, o cantar o amor. Sem a certeza de seu efeito e da realização amorosa, a voz poética se firma como última possibilidade de perpetuar o amor. Transitando entre duas pessoas ao longo do livro, a amante e o amado, esses versos inserem uma terceira pessoa na trama amorosa, Deus, que, ao tecer a vida, tece a morte, é o Artífice desse ser perecível, "poeira", que ama o que não tem nome, o qual, antecipando-se a seu criador, devora o ser que ama e transforma o amor em nada, "o pó".

Assim, o "como se" reiterativo em todo o poema é quase um Leitmotiv que, somado ao ritmo empeçado, na pouca fluência dos versos, e à sintaxe permissiva dos verbos no subjuntivo do pretérito descerram um efeito simbólico de embotamento frente ao real. Na possibilidade indagadora mal-resolvida, na tessitura das hipóteses erigidas, o sujeito tenta compensar sua fome de saber o amor tão distante daquilo que experimenta. O "como se" parece ainda resvalar no seu contrário desde o verso inicial: quer dizer, então, que não é verdade, quer dizer que Aquele não ouve arrebatado os cantares dela e que ela a cada noite não se despede destilando felicidade? Mais: quer dizer que o tu intratextual não é amante, nem está de luto, por isso, talvez no plano real, não merecesse 
o consolo de um Pai, o maior deles, o Tecelão do destino, da vida e da morte, da "teia"? E, por último, quer dizer que amá-lo não é perfeito? E por que não? Porque amá-lo na sua finitude é inevitavelmente dizer adeus? O poema se fecha numa pergunta suspensiva na medida em que persegue o arquiteto "disso sem nome", o "ISSO" - demonstrativo em maiúsculas -, o que parece apontar a inépcia do eu no entendimento da autoobsessão em torno do amor e sua fome, anelo de completude jamais serenado.

A poesia, então, voz oracular que transmite os mistérios dos deuses aos homens, desde que Orfeu desceu aos mundos ínferos, não conhece a via que retorna ao sagrado, pois aqui seus ressoos ao divino não passam de uma dúvida, de uma possibilidade. Afinal, se Deus é amor, Ele mesmo é perecível e, desta forma, o amor não contradiz, também, a sua origem cristã? Deus e o amor se confundem numa teia ardilosa, cujo sentido maior é o da dissolvência. Então, como seria possível que Deus ainda se comovesse com o clamor dos homens e com o amor destes uns pelos outros quando, Ele mesmo, o Amor, é Cego e Seguidor daquilo que jamais se basta a si mesmo?

O canto de Orfeu, que outrora enternecia até o rude Senhor do Hades, levando-o a ceder uma alma de seu reino como dádiva a um amor infinito e recompensa pelo lamento pungente da lira vibrante, aqui não alcança o objeto amado. Deus não dá o dote, a posse tão desejada. Antes, Ele, numa incompreensível piedade, dá o sono-morte, faz calar a voz da celebração e do lamento, ainda que o sujeito lírico veja-O comovido com sua situação de desolação e desengano. De igual forma, o amado não se renderia ao amante, se afastaria, com a boca marcada de esplendor - para os índios caraíbas, colibri significa "área resplandecente" -, iluminado e satisfeito, levando consigo as prendas colhidas. Contudo, são possibilidades, aspirações, porque o sujeito-lírico ainda não é o amante correspondido.

O amor mendigo desconhece as porias da satisfação e da morada definitiva, “porque humana / És apenas poeira", é campo do transitório e do efêmero, porque, de igual forma, o amor do outro também é pó e perecível. Deus/amor é Cego e Seguidor, elementos dos dois últimos versos que retomam o primeiro verso do primeiro poema, "Que este amor não me cegue nem me siga.”. Considerando que esse Deus/amor é, a princípio, o Deus cristão, a poeta fere a teologia do Deus luz do mundo, princípio da 
razão, da clarividência absoluta, da lâmpada que conduz os passos pelo caminho iluminado e regenera os homens, conduzindo-os de volta às cortes celestiais, ao conhecimento imutável. Como a experiência prova o contrário, exibindo um amor cego, que age contra a razão e a sabedoria, a literatura e as artes especializaram-se na expressão desse amor irracional, cego, inconsequente, próximo dos atos de uma criança. A Renascença descarta o amor adulto e lúcido da Idade Média, pois

vê reaparecer o motivo cultivado na Antiguidade do puer alatus (menininho com asas) e desenvolver-se aquele do Amor cego: os pintores, notadamente Piero della Francesca, representam-no com os olhos vendados, simbolizando assim o que o sentimento amoroso tem de arbitrário e de inconsciente (LÉVY, 2005, p. 323).

Que outros efeitos o amor cego provocaria, a não ser a cegueira? As asas do amor ruflam constantemente, em sua original insatisfação e efemeridade. Desprovido de olhos, não é contemplativo nem vidente. Pelas asas, é o eterno Seguidor sem morada definitiva, sempre alçando a outras e mais outras paragens, sempre em despedida, sempre perdido.

O sentimento desse amor perecível, vão, persiste em nós, "Como se fosse vão te amar e por isso perfeito. / Amar o perecível, o nada, o pó, é sempre despedir-se.” (p.26), e acorda em nossa memória as redondilhas desse outro poeta, Drummond, que tanto se entregou à "mineração do outro", como no poema intitulado "Memória":

\footnotetext{
Amar o perdido deixa confundido este coração.

Nada pode o olvido contra o sem sentido apelo do Não.

As coisas tangíveis tornam-se insensíveis à palma da mão.

Mas as coisas findas, muito mais que lindas, essas ficarão.
}

(ANDRADE, 1992, p. 204). 
Se o tangível é insensível, como explicar o desespero de Narciso, que se vê tomado de furor e lamento, ao conscientizar-se de que a imagem amada sempre lhe escaparia? Mais uma vez entram os genitores de Eros, Poros e Penia, pois a engenhosidade do primeiro é capaz de superar a carência e a miséria, assim como " $\mathrm{O}$ amor e sua fome" levam a amante a criar e encontrar expedientes para mitigar seu suplício.

\section{REFERÊNCIAS}

ANDRADE, C. D. de. Poesia e prosa. Rio de Janeiro: Aguilar, 1992.

BLANCO, R. A. Jardim de flores. Disponível em:

<http://www.jardimdeflores.com.br/CURIOSIDADES/beija.htmlgt;. Acesso em: 14 fev. 2009.

BRANDÃO, J. de S. Mitologia grega. Petrópolis: Vozes, 2005.

CARVALHO, R. T. de. Insights de uma mente confusa. Disponível em:

<http://rtcarvalho.blogspot.com/>. Acesso em: 12 fev. 2009.

CIRLOT, J.-E. Dicionário de símbolos. Trad.: Rubens Eduardo Ferreira Frias. São Paulo: Moraes, 1984.

DROZ, G. Os mitos platônicos. Trad.: Maria Auxiliadora Ribeiro Keneipp. Brasília: UnB, 1997.

FREUD, S. Além do princípio de prazer. In: Obras psicológicas completas. Rio de Janeiro: Imago, 1996.

HILST, H. Cantares. São Paulo: Globo, 2002.

KAREN. Tulipa. Disponível em: < http://karen-rs.blogspot.com/>. Acesso em: 12 fev. 2009.

KRISTEVA, J. Histórias de amor. Trad.: Leda Tenório da Motta. Rio de Janeiro: Paz e Terra, 1988.

LÉVY, A.-D. Eros. In: BRUNEL, P. (Org.). Dicionário de mitos literários. Trad.:

Carlos Sussekind et al. Rio de Janeiro: J. Olympio, 2005.

MAY, R. Eros e repressão - amor e vontade. Trad.: Áurea Brito Weissenberg. Petrópolis: Vozes, 1973.

OVÍDIO. Metamorfoses. Trad. Vera Lúcia Leitão Magyar. São Paulo: Madras, 2003. PLATÃO. Diálogos. Seleção de textos de José Américo Motta Pessanha. Traduções e notas de José Cavalcante de Souza et al. São Paulo: Abril Cultural, 1979 (Os pensadores). 
[1] Todos os poemas de Hilda Hilst mencionados neste estudo são da obra Cantares (São Paulo: Globo, 2002), que, a partir de agora, será indicada apenas pelo número da página em que se insere o poema.

[2] Blog Insights de uma mente confusa. Disponível em: <http://rtcarvalho.blogspot.com/>. Acesso em: 12 fev. 2009.

[3] Lenda de autoria desconhecida facilmente encontrada em qualquer blog sobre tulipas como, por exemplo, Tulipa, disponível em < http://karen-rs.blogspot.com/>, acesso em 12 fev. 2009. 